\title{
What is the safest mode of delivery for extremely preterm cephalic/non-cephalic twin pairs? A systematic review and meta- analyses
}

Catherine Dagenais ${ }^{1}$, Anne-Mary Lewis-Mikhael ${ }^{2}$, Marinela Grabovac ${ }^{2}$, Amit Mukerji ${ }^{3}$ and Sarah D. McDonald ${ }^{1,2^{*}}$

\begin{abstract}
Background: Given the controversy around mode of delivery, our objective was to assess the evidence regarding the safest mode of delivery for actively resuscitated extremely preterm cephalic/non-cephalic twin pairs before 28 weeks of gestation.

Methods: We searched Cochrane CENTRAL, MEDLINE, EMBASE and http://clinicaltrials.gov from January 1994 to January 2017. Two reviewers independently screened titles, abstracts and full text articles, extracted data and assessed risk of bias. We included randomized controlled trials and observational studies. Our primary outcome was a composite of neonatal death ( $<28$ days of life) and severe brain injury in survivors (intraventricular hemorrhage grade $\geq 3$ or periventricular leukomalacia). We performed random-effects meta-analyses, generating odds ratios with 95\% confidence intervals for the first and second twin separately, and for both twins together. We assessed the risk of bias using a modified Newcastle Ottawa Scale (NOS) for observational studies and used Grading of Recommendations Assessment, Development and Evaluation approach (GRADE).
\end{abstract}

Results: Our search generated 2695 articles, and after duplicate removal, we screened 2051 titles and abstracts, selecting 113 articles for full-text review. We contacted 36 authors, and ultimately, three observational studies met our inclusion criteria. In cephalic/non-cephalic twin pairs delivered by caesarean section compared to vaginal birth at $24^{+0}-27^{+6}$ weeks the odds ratio for our composite outcome of neonatal death and severe brain injury for the cephalic first twin was 0.35 (95\% Cl 0.00-92.61, two studies, $\left.I^{2}=76 \%\right), 1.69$ for the non-cephalic second twin (95\% Cl 0.04-72.81, two studies, $I^{2}=55 \%$ ) and 0.83 for both twins (95\% Cl 0.05-13.43, two studies, $\left.I^{2}=56 \%\right)$. According to the modified Newcastle Ottawa Scale we assessed individual study quality as being at high risk of bias and according to GRADE the overall evidence for our primary outcomes was very low.

Conclusion: Our systematic review on the safest mode of delivery for extremely preterm cephalic/non-cephalic twin pairs found very limited existing evidence, without significant differences in neonatal death and severe brain injury by mode of delivery.

Keywords: Twin, Extremely preterm, Extremely low birth weight, Vaginal delivery, Caesarean section, Breech presentation

\footnotetext{
* Correspondence: mcdonals@mcmaster.ca

${ }^{1}$ Department of Obstetrics \& Gynecology, McMaster University, 1280 Main St

W, HSC 3N52B, Hamilton, ON L8S 4K1, Canada

${ }^{2}$ Department of Health Research Methods, Evidence, and Impact, McMaster

University, 1280 Main St W, Hamilton, ON L8S 4K1, Canada

Full list of author information is available at the end of the article
} 


\section{Background}

Extreme prematurity, the birth of an infant before 28 weeks' gestation, contributes significantly to infant mortality [1] and childhood morbidity [2]. Extremely preterm births represent approximately $0.2 \%$ of singleton births [3, 4], but $4.1 \%$ of twins births [5]. In extremely preterm twins from 24 to 27 weeks, the most frequent combination of presentations is cephalic/non-cephalic (42.5\%) followed by cephalic/cephalic (25.3\%) and noncephalic/non-cephalic (22.6\%) which differs significantly from term proportions [6].

Controversy remains as to the influence of mode of delivery on neonatal outcomes in extremely preterm singletons and twins in general. Some [7, 8], but not all studies [9] have raised concerns about the safety of vaginal birth for extremely preterm breech singleton infants. In a recent meta-analysis, Grabovac et al. 2017 found that caesarean delivery was associated with a $40 \%$ decrease in the odds of mortality and $40 \%$ decrease in odds of severe intraventricular hemorrhage (IVH; grades $\geq 3$ ) in extremely preterm breech singletons who were actively resuscitated [10].

In twins, determining the safest mode of delivery is more complex than in singletons, since beyond gestational age, birth order and various presentation combinations need to be considered. For cephalic/noncephalic twins above 32 weeks, the 2013 randomized controlled trial by Barrett et al. found that trial of labor is safe [11], but due to their inclusion criteria, could not provide guidance on twin birth before 32 weeks.

While a caesarean section is typically performed when the first twin presents as non-cephalic, vaginal birth is generally attempted when both twins are cephalic [12-15]. When the first twin is cephalic and the second is non-cephalic, there is less clinical consensus, leading to variations in clinical practice depending on the clinicians' level of experience, training, and the prevailing obstetrical culture in their location of practice [12-15].

When the second twin is breech, the delivery involves a sequence of events which differs from a singleton breech delivery, including delivery through an already dilated cervix, potential for manoeuvres such as breech extraction and external cephalic version, precluding direct extrapolation of singleton data to the mode of delivery of twins. In face of all these considerations, we decided to perform a systematic review of the literature to assess the evidence regarding the safest mode of delivery of extremely preterm cephalic/non-cephalic twin pairs who were actively resuscitated.

\section{Methods}

We planned to follow the Cochrane Handbook for Systematic Reviews of Interventions (Version 5.1.0) for randomized studies and the PRISMA guidelines for observational studies [16, 17]. We registered this protocol on PROSPERO (CRD42017056295).

\section{Information sources}

We developed separate search strategies with the assistance of an experienced librarian for each database, consisting of medical subject headings (MeSH) and multipurpose terms (.mp), which we used to search Cochrane CENTRAL, MEDLINE and EMBASE from January 1,1994 - the year the guidelines for the use of antenatal corticosteroid were published -, until January 12, 2017, without language restriction (Additional file 1). We also searched for unpublished randomized controlled trials (RCT) on http://clinicaltrials.gov using the keywords "twin", "twins", "multiple pregnancy" and "multiple pregnancies". We imported all references into a bibliographic software (Endnote X8). We manually searched the references of included studies and relevant systematic reviews for additional articles. We consulted a Maternal Fetal Medicine expert for knowledge on other studies published in this area.

\section{Eligibility}

We planned to include all published randomized controlled trials and observational studies (cohort and case-control) comparing mode of delivery in extremely preterm $\left(22^{+0}\right.$ and $27^{+6}$ weeks $)$ dichorionic or monochorionic-diamniotic twins presenting as a cephalic/ non-cephalic pair who were actively resuscitated. If a study focused on mode of delivery in twins, but did not stratify the data according to gestational age or presentation, we contacted the authors to obtain these data. If the study population was defined by birth weight only, without data on gestational age, we included twins weighing $\leq 1000 \mathrm{~g}$, which is approximately the 90th percentile for twins born at 27 weeks [18].

We excluded other types of publications (e.g. reviews, editorials, commentaries, case studies, conference proceedings, studies published only as abstracts, etc.). We excluded studies with insufficient data, such as $<10$ twin pairs total or less than five twin pairs per comparison group (i.e. caesarean and vaginal delivery). We excluded studies with data collected prior to 1994, regardless of publication date. If the data spanned 1994, we contacted the authors to confirm antenatal corticosteroid (ANCS) use was the standard of practice at the time of data collection, and included the study if either the authors confirmed that this was the case or were able to provide separate data for after 1994.

We focused on high-income countries, as they routinely provide active resuscitation for all infants $\geq 25$ weeks, and variably offer resuscitation at 22, 23 or 24 weeks [19], while middle- and low-income countries typically do not. If data on active resuscitation were not 
provided in the study, we contacted the author to confirm that active resuscitation was planned for all included infants or to request separate data for the actively resuscitated infants only. If the author did not respond, but the study originated from a high-income country, we assumed that resuscitation was planned for all neonates $\geq 25$ weeks. For middle and low incomes countries, if the author did not respond, we excluded the study.

We planned to exclude monochorionic-monoamniotic twins, conjoined twins, twins resulting from fetal reduction of a higher-order pregnancy, twin pairs with one or two fetal deaths before labour, twins with congenital anomalies and asynchronous delivery of the second twin where the aim was to prolong the pregnancy. We intended to exclude twins delivered by caesarean section as a result of an absolute contra-indication to vaginal delivery (e.g. fetal compromise before labour, fetal congenital anomaly, placenta or vasa praevia, uterine rupture, etc.).

Our primary outcome was a composite consisting of: 1) neonatal death defined as death in the first 28 days of life [20] and/or 2) severe brain injury (SBI) [21] among survivors, defined as severe intraventricular hemorrhage (IVH grades $\geq 3$ based on Papile's grading) or periventricular leukomalacia (PVL).

Our main secondary outcomes were the components of our primary composite outcome examined individually: neonatal death, and in survivors, severe brain injury. Another main secondary outcome was overall perinatal mortality (intrapartum death and neonatal death). We examined these outcomes separately in each twin individually according to birth order, and in both twins as pairs together. Our other infant and maternal secondary outcomes are presented in Additional file 2.

\section{Data collection}

Two reviewers (CD and AMLM) independently reviewed the titles, abstracts, and full texts. As there are known issues with the kappa statistic (low kappa despite high agreement), we calculated percent agreement to assess inter-reviewer agreement on study inclusion. We used a piloted data collection form to extract data on baseline characteristics, exposures of interest, outcomes, and risk of bias assessment. Discrepancies between reviewers were resolved through discussion, with a third reviewer (SDM) available if necessary.

\section{Risk of bias assessment}

We planned to use the Cochrane Collaboration's Risk of Bias (RoB) tool for randomized control trials and the modified Newcastle-Ottawa Scale (NOS) for observational studies to assess risk of bias of our included studies $[16,22]$.
The Newcastle Ottawa Scale uses three categories, Selection, Comparability and Outcomes, to assess bias in observational studies. We modified the Selection and Outcomes categories by removing 1) ascertainment of exposure, since our exposures of interest (e.g. caesarean section or vaginal delivery) was only obtained through a secure medical record, 2) demonstration that the outcome of interest was not present at the beginning of the studies as the infant and maternal outcomes would not have been present at the time of the caesarean section or vaginal delivery, and 3) whether follow-up was long enough for the outcomes to occur because our outcomes of interest are assumed to have occurred after birth and before discharge from the hospital. We modified the Comparability category so that four points would be awarded for addressing key potential confounders. Those were identified in consultation with Maternal Fetal Medicine and Neonatology experts and were 1) caesarean section for fetal distress, 2) outborn status, 3) antenatal corticosteroid administration (ANCS) and 4) clinical chorioamnionitis. The study was awarded one point for each confounder it addressed for a maximum of four points. Hence, our modified scale awarded up to eight points in total. Since there are no validation studies on a modified scale, we determined that a study scoring eight points would be considered a high-quality study at low risk of bias. A study scoring seven points would be considered of moderate quality and at moderate risk of bias and a study scoring six points or less of low quality and at high risk of bias.

\section{Data analysis}

Since we expected between-study heterogeneity, we performed random-effects meta-analyses, generating odds ratios (OR) and 95\% confidence intervals (95\% CI). We assessed heterogeneity using $\mathrm{I}^{2}$ statistic; we considered $\mathrm{I}^{2}$ values $0-40 \%$ to be low, $30-60 \%$ moderate, $50-90 \%$ substantial and $75-100 \%$ considerable heterogeneity [16, 17]. We intended to analyze our primary composite and main secondary outcomes according to pre-planned gestational week categories $22^{+0}-23^{+6}, 24^{+0}-25^{+6}$ and $26^{+0}$ $27^{+6}$ weeks and pooled together. We planned to separately pool RCT and observational data, to separately pool adjusted and unadjusted data, to separately analyze data from middle- and low-income countries, and to calculate the number needed to treat (NNT) for significant outcomes. All analyses were performed using Review Manager (RevMan) Version 5.3 [23].

\section{Risk of bias across studies}

We used the Grading of Recommendations, Assessment, Development, and Evaluation (GRADE) system to assess the overall quality of evidence for our primary outcome, 
i.e. the confidence that an outcome's effect size is close to the intervention's true effect [22].

We used the GRADE system to rate the quality of evidence for each outcome as high, moderate, low or very low. GRADE recommends that RCTs start as highquality evidence and observational studies as low-quality evidence, which is then either downgraded (RCTs and observational) or upgraded (observational). The evidence is downgraded by the presence of risk of bias, inconsistency, indirectness, imprecision or publication bias. We assessed those in the following manner: 1) for RCTs, we planned to assess risk of bias using the Cochrane's RoB and for observational studies using the modified NOS; 2) Inconsistency was assessed by substantial heterogeneity as indicated by $\mathrm{I}^{2}$ values above $50 \%$; 3) Indirectness was assessed by differences in the population, intervention, or outcome, or indirect comparison; 4) Imprecision was assessed by checking whether 95\% CIs overlap no effect and/or fail to exclude important benefit/harm; 5) Assessment of publication bias was planned with funnel plots for outcomes with 10 studies or more [24]. The evidence is upgraded in the presence of a large effect, dose-response effect and if all potential confounding would minimize the demonstrated effect.

\section{Subgroup analyses}

In addition to stratification by gestational age categories, we intended to separately analyze our main secondary outcomes by birth weight categories $(<500 \mathrm{~g}, 500-999 \mathrm{~g}$ and $<1000 \mathrm{~g}$ ). We intended to include the infants who died intrapartum in the adjusted analysis if active resuscitation was planned for them, as excluding them could result in overestimation of the benefits of either mode of delivery.

Data permitting, we intended to address the a priori selected key confounders previously mentioned through subgroup analysis: caesarean section for fetal distress, outborn status, ANCS administration and clinical chorioamnionitis. We also intended to collect information on other potential confounders: cause of prematurity, gestational age at preterm premature rupture of the membranes (PPROM), presence of abruption, presence of growth restriction, weight discrepancy between twins, length of labour, length of birth interval between twins, magnesium sulfate administration before birth, surfactant administration after birth, exact presentation of second twin (breech vs transverse), and maneuvers required for vaginal delivery of the second twin (e.g. external cephalic version versus breech extraction).

We intended to perform a sensitivity analysis by removing low and moderate quality studies to obtain effect estimates using high quality studies only. We also planned to perform a sensitivity analyses by removing studies that excluded intrapartum fetal demise from their study population.

\section{Results}

\section{Search strategy}

Our search retrieved a total of 2695 abstracts (Cochrane CENTRAL $=193$, MEDLINE $=611$, EMBASE $=1881$, Fig. 1). We identified an additional prospective cohort study from http://clinicaltrials.gov, with a planned subgroup analysis for twins less than 28 weeks, however the initial publication included solely data for twins more than 32 weeks [25], and the authors were unable to provide additional data after contact.

After removing duplicates, we screened 2051 titles and abstracts, selecting 113 full-text articles for review. The initial agreement between reviewers was $92 \%$ for full text review. We preliminarily included 36 studies, whose authors we contacted to obtain additional information (Fig. 1, Additional file 3). The response rate was $54 \%$. Out of the 19 authors who responded, 14 could not provide the requested data [26-39], two authors contributed data we could not use [40,41], and three authors provided data we included in our meta-analyses [42-44]. The main reasons for not being able to include studies without author response were absence of stratification of data by gestational age $<28$ weeks or birth weight $<1000 \mathrm{~g}$, by birth order or by presentation in the original paper (Additional file 3). For the 16 out of 19 authors (84\%) who responded favorably to our request for additional information, the reason for not being able to provide data or include the provided data in the study were the same (Additional file 3).

\section{Description of studies}

We included three observational studies from highincome countries: France, Israel and Slovenia. The analyzed data were collected between 2003 and 2012 (Table 1). The comparison in all three studies was mode of delivery - caesarean section or vaginal delivery - for both twins.

Outcomes were not stratified for our population of interest in the original studies, namely cephalic/noncephalic twin pairs $<28$ weeks, and hence the data were provided to us by all three authors upon request. Gestational age ranged from $22^{+0}-27^{+6}$ weeks across the three studies, and the outcomes were provided separately for each twin. One set of twins underwent a combined delivery, whereby the first twin was delivered vaginally and the second twin by caesarean section in Boukerrou 2011 [43]. The outcomes for this twin pair were included in the respective mode of delivery of each of the twin. We initially planned to include studies with at least 10 twin pairs, however, due to the paucity of studies meeting our inclusion criteria, and in order to maximize the number of twins, we included studies with eight or more twin pairs. 


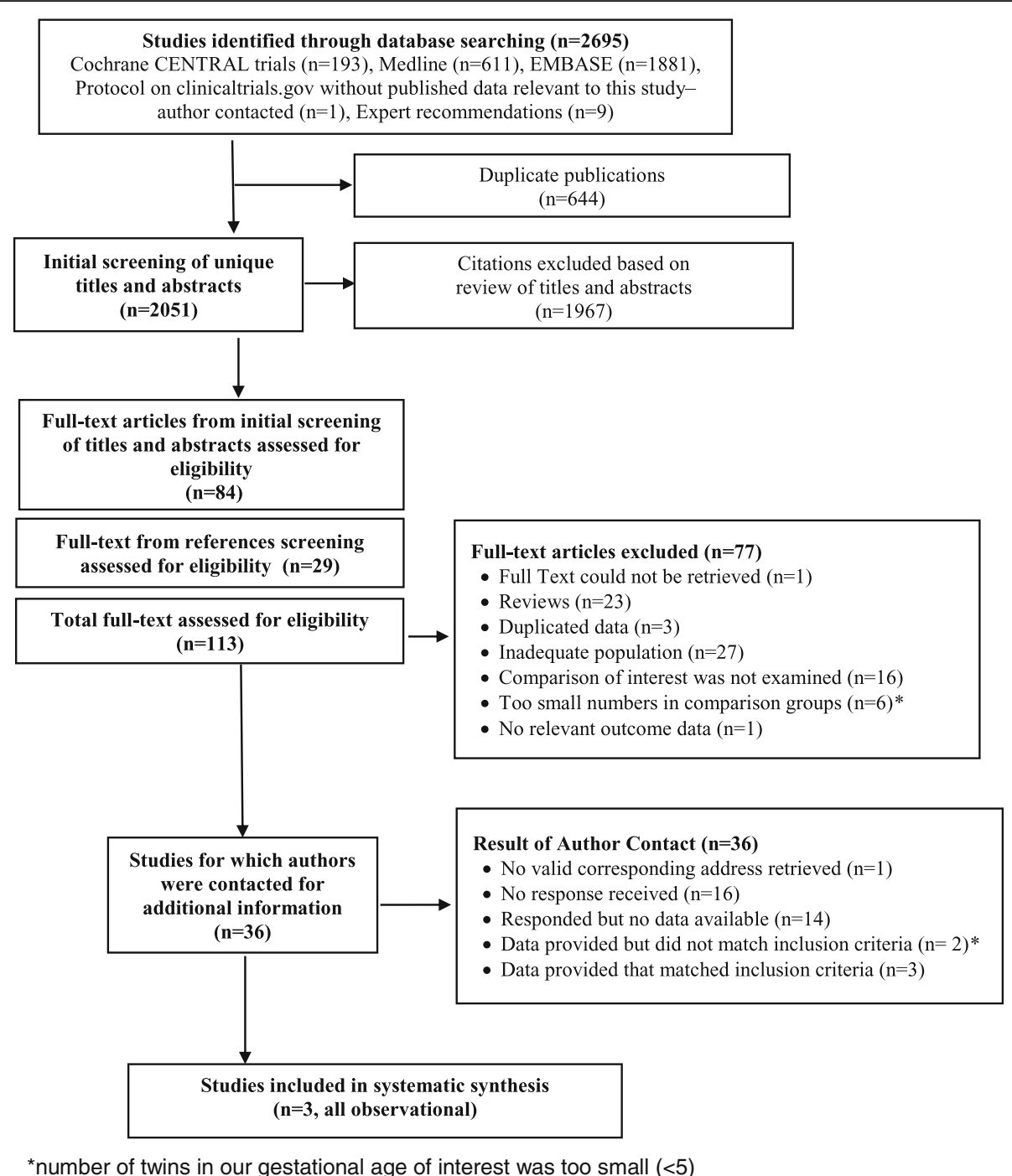

Fig. 1 Study flowchart for a systematic review/meta-analyses on the safest mode of delivery for extremely preterm cephalic/non-cephalic twin pairs

\section{Risk of bias assessment}

According to our modified NOS, all three studies were at high risk of bias, scoring three points out of the maximum of eight (Table 2). All studies lost one point in the Outcome category, as they did not account for loss to follow-up. None of the studies addressed any of the key confounders for our outcome of interest (i.e. caesarean section for fetal distress, outborn status, ANCS use and clinical chorioamnionitis), and hence no points were allotted for the Comparability criteria.

All twins from Boukerrou [43] and Barzilay [44] were planned for active resuscitation. Bricelj 2016 [42] could not confirm active resuscitation for all twins, and therefore we included their data only for twins born at $25^{+0}-27^{+6}$ weeks in our analysis.

\section{Effects of mode of delivery}

In cephalic/non-cephalic twin pairs delivered by caesarean section compared to vaginal birth at $24^{+0}-27^{+6}$ weeks the odds ratio for our composite outcome of neonatal death and severe brain injury for the cephalic first twin was 0.35 (95\% CI 0.00-92.61, two studies, $\mathrm{I}^{2}=76 \%$, Fig. 2, Table 3), 1.69 for the non-cephalic second twin (95\% CI 0.04-72.81, two studies, $\mathrm{I}^{2}=55 \%$ ) and 0.83 for both twins (95\% CI 0.05-13.43, two studies, $\mathrm{I}^{2}=56 \%$ ).

The odds ratios of neonatal death were for twins delivered between $24^{+0}-27^{+6}$ weeks by caesarean section compared to vaginally were 0.36 for the cephalic first twins (95\% CI 0.03-4.40, two studies, $\mathrm{I}^{2}=0 \%$, Fig. 3), 1.31 for the non-cephalic second twins (95\% CI $0.02-$ 79.60 , two studies, $\mathrm{I}^{2}=66 \%$ ), and 0.73 for both twins together (95\% CI 0.10-5.46, two studies, $\mathrm{I}^{2}=26 \%$ ). 
Table 1 Study characteristics in a systematic review/meta-analyses on the safest mode of delivery for extremely preterm cephalic/ non-cephalic twin pairs

\begin{tabular}{|c|c|c|c|}
\hline $\begin{array}{l}\text { Author, } \\
\text { Publication Year, } \\
\text { Country; Study } \\
\text { Period; Study } \\
\text { Design }\end{array}$ & Inclusion and exclusion criteria & Usual practice regarding twin delivery & Outcomes in original study ${ }^{*}$ \\
\hline $\begin{array}{l}\text { Boukerrou, } 2011 \\
\text { France; } 2006- \\
\text { 2011; Prospective } \\
\text { cohort }\end{array}$ & $\begin{array}{l}\text { Inclusion: All twin births during the study } \\
\text { period Exclusion: HOM, stillbirths, births } \\
\text { less } 24 \text { weeks }\end{array}$ & $\begin{array}{l}\text { For non-cephalic second twin, breech ex- } \\
\text { traction with or without internal podalic } \\
\text { version is preferred. }\end{array}$ & $\begin{array}{l}\text { Neonatal death (0-28 days), graded } \\
\text { IVH and PVL (in provided data only) }\end{array}$ \\
\hline $\begin{array}{l}\text { Barzilay, 2015 } \\
\text { Israel; 2004-2011; } \\
\text { Retrospective } \\
\text { cohort }\end{array}$ & $\begin{array}{l}\text { Inclusion: All twin births with second twin } \\
\text { birthweight less } 1500 \mathrm{~g} \text { Exclusion: Birth } \\
\text { less } 24 \text { weeks, fetal death of one or both } \\
\text { twins, major malformation in one or both } \\
\text { twins }\end{array}$ & $\begin{array}{l}\text { Allow vaginal delivery of cephalic-non- } \\
\text { cephalic twin pairs regardless of EFW or } \\
\text { GA if EFW of twin B is not } 20 \% \text { higher than } \\
\text { that of twin A. Breech extraction is pre- } \\
\text { ferred for delivering non-cephalic twin B. }\end{array}$ & $\begin{array}{l}\text { Apgar } 5 \text { min, Cord blood PH, Neonatal } \\
\text { death (not otherwise specified), Birth } \\
\text { trauma, RDS, Sepsis, NEC, IVH, } \\
\text { Composite adverse neonatal } \\
\text { outcome (neonatal death, RDS, sepsis, } \\
\text { NEC, or IVH grade } \geq 3 \text { ) }\end{array}$ \\
\hline $\begin{array}{l}\text { Bricelj, } 2016 \\
\text { Slovenia; 2003- } \\
\text { 2012; } \\
\text { Retrospective } \\
\text { cohort }\end{array}$ & $\begin{array}{l}\text { Inclusion: All deliveries from } 22 \text { weeks or } \\
\text { birth weight } 500 \mathrm{~g} \text { up to less than } \\
37 \text { weeks Exclusion: Delayed births, } \\
\text { combined deliveries, stillbirths (in provided } \\
\text { data only) }\end{array}$ & Not stated & TTN, RDS, Ventilation need \\
\hline
\end{tabular}
HOM high order multiple pregnancies, EFW estimated fetal weight, GA gestational age, $I V H$ intraventricular hemorrhage, $P V L$ periventricular leukomalacia, $R D S$ respiratory distress syndrome, NEC necrotizing enterocolitis, $T N$ transient tachypnea of the newborn ${ }^{*}$ Outcomes provided by the authors for twins less 28 weeks are bolded

The odds ratios of severe brain injury in survivors, for twins delivered between $24^{+0}-27^{+6}$ weeks by caesarean section compared to vaginally were 0.59 for the cephalic first twins (95\% CI 0.00-154.35, two studies, $\mathrm{I}^{2}=74 \%$, Fig. 4), 1.00 for the non-cephalic second twins $(95 \%$ CI $0.02-40.28$, two studies, $\left.\mathrm{I}^{2}=\mathrm{N} / \mathrm{A}\right)$, and 0.76 for both twins together (95\% CI $0.03-17.34$, two studies, $\mathrm{I}^{2}=48 \%$ ). Data on severe brain injury were missing for five surviving twins out of fourteen (36\%) in the data by Boukerrou 2011 [43] and for two surviving twins out of fourteen in the data from Barzilay 2015 [44].

For our secondary outcomes, the odds ratios of respiratory distress syndrome for twins delivered between $25^{+0}-27^{+6}$ weeks by caesarean section compared to vaginally were 0.23 for the cephalic first twins $(95 \% \mathrm{CI}$ 0.01-6.25, two studies, $\mathrm{I}^{2}=$ N/A, Fig. 5), 1.60 for the non-cephalic second twins (95\% CI 0.12-20.99, two studies, $\left.\mathrm{I}^{2}=\mathrm{N} / \mathrm{A}\right)$, and 0.77 for both twins together (95\% CI $0.10-5.87$, two studies, $\left.\mathrm{I}^{2}=0 \%\right)$. Data for other secondary infant and maternal outcomes were not available.

We were unable to stratify any of our outcomes by gestational age categories, as the sample sizes were too small. We could not perform any of the planned subgroup analyses due to lack of data in primary studies. Since all studies were at high risk of bias, we could not perform the planned sensitivity analyses. We were unable to pool adjusted data, since that data was lacking for our population of interest in the primary studies.

\section{Quality of the evidence (GRADE)}

We downgraded the quality of evidence due to serious risk of bias and imprecision, but not due to inconsistency and

Table 2 Bias assessment in a systematic review/meta-analyses on the safest mode of delivery for extremely preterm cephalic/noncephalic twin pairs

\begin{tabular}{|c|c|c|c|c|c|c|c|c|c|}
\hline \multirow{2}{*}{$\begin{array}{l}\text { Study ID } \\
\text { Author, } \\
\text { Year, } \\
\text { Country }\end{array}$} & \multirow[t]{2}{*}{ Total } & \multicolumn{2}{|l|}{ Selection } & \multicolumn{2}{|l|}{ Outcome } & \multicolumn{4}{|l|}{ Comparability } \\
\hline & & $\begin{array}{l}\text { Representativeness } \\
\text { of the exposed } \\
\text { cohort }\end{array}$ & $\begin{array}{l}\text { Selection of the } \\
\text { non- exposed } \\
\text { cohort }\end{array}$ & $\begin{array}{l}\text { Assessment } \\
\text { of outcome }\end{array}$ & $\begin{array}{l}\text { Adequacy of } \\
\text { follow up of } \\
\text { cohorts }\end{array}$ & $\begin{array}{l}\text { Emergent } \\
\text { caesarean for } \\
\text { fetal distress }\end{array}$ & $\begin{array}{l}\text { Clinical } \\
\text { Chorioamnionitis }\end{array}$ & $\begin{array}{l}\text { Outborn } \\
\text { Status }\end{array}$ & ANCS \\
\hline $\begin{array}{l}\text { Boukerrou, } \\
2011 \\
\text { France }\end{array}$ & $3 / 8$ & $\star$ & $\star$ & $\star$ & - & - & - & - & - \\
\hline $\begin{array}{l}\text { Barzilay, } \\
2015 \text { Israel }\end{array}$ & $3 / 8$ & $\star$ & $\star$ & $\star$ & - & - & - & - & - \\
\hline $\begin{array}{l}\text { Bricelj, } \\
2016 \\
\text { Slovenia }\end{array}$ & $3 / 8$ & $\star$ & $\star$ & $\star$ & - & - & - & - & - \\
\hline
\end{tabular}




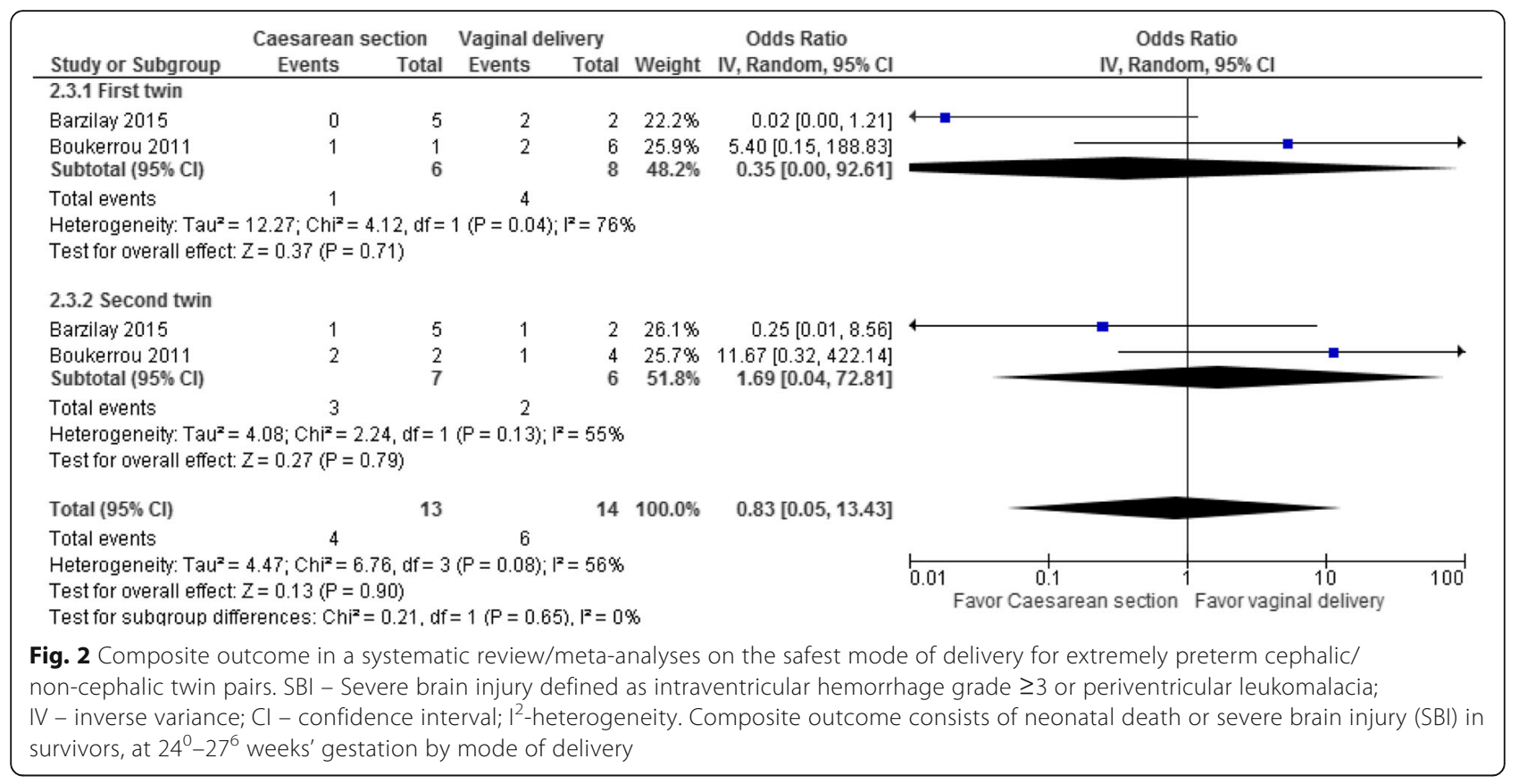

indirectness. Publication bias could not be assessed, as the number of studies was $<10$ per outcome. We could not upgrade the evidence, as a large effect was not present, and confounding was not accounted for; the doseresponse was not applicable for our meta-analyses. The overall quality of evidence was very low for our primary composite outcome (neonatal death or SBI), for neonatal death and for respiratory distress syndrome (Table 3, Additional file 4).

\section{Discussion}

\section{Main findings}

In this systematic review on the safest mode of delivery for extremely preterm cephalic/non-cephalic twin pairs, we found scarce data. Analysis did not favour either caesarean section or vaginal birth. The confidence intervals were wide and encompassed one for our primary composite outcome of neonatal death and severe brain injury, as well as for neonatal death alone or severe brain

Table 3 Outcomes in a systematic review/meta-analyses on the safest mode of delivery for extremely preterm cephalic/noncephalic twin pairs

\begin{tabular}{|c|c|c|c|c|c|c|c|c|}
\hline Outcome & $\begin{array}{l}\text { GA category } \\
\text { (weeks) }\end{array}$ & $\begin{array}{l}\text { Number of } \\
\text { studies }\end{array}$ & & $\mathrm{CS}(\mathrm{n} / \mathrm{N})$ & $V D(n / N)$ & OR $(95 \% \mathrm{CI})$ for CS & $1^{2}(\%)$ & $\begin{array}{l}\text { GRADE Quality } \\
\text { of the evidence* }\end{array}$ \\
\hline \multirow{3}{*}{$\begin{array}{l}\text { Neonatal death or } \\
\text { Severe Brain Injury } \\
\text { in survivors }\end{array}$} & \multirow[t]{3}{*}{$24^{+0}-27^{+6}$} & \multirow[t]{3}{*}{2} & First twin (cephalic) & $1 / 6$ & $4 / 8$ & OR 0.35 (0.00-92.61) & 76 & \multirow[t]{3}{*}{ Very Low } \\
\hline & & & Second twin (non-cephalic) & $3 / 7$ & $2 / 6$ & OR 1.69 (0.04-72.81) & 55 & \\
\hline & & & Both twins & $4 / 13$ & $6 / 14$ & OR $0.83(0.05-13.43)$ & 56 & \\
\hline \multirow[t]{3}{*}{ Neonatal death } & \multirow[t]{3}{*}{$24^{+0}-27^{+6}$} & \multirow[t]{3}{*}{2} & First twin (cephalic) & $0 / 7$ & $2 / 10$ & OR $0.36(0.03-4.40)$ & 0 & \multirow[t]{3}{*}{ Very low } \\
\hline & & & Second twin (non-cephalic) & $2 / 8$ & $2 / 9$ & OR 1.31 (0.02-79.60) & 66 & \\
\hline & & & Both twins & $2 / 15$ & $4 / 19$ & OR $0.73(0.10-5.46)$ & 26 & \\
\hline \multirow{3}{*}{$\begin{array}{l}\text { Severe Brain Injury } \\
\text { in survivors }\end{array}$} & \multirow[t]{3}{*}{$24^{+0}-27^{+6}$} & \multirow[t]{3}{*}{2} & First twin (cephalic) & $1 / 6$ & $2 / 6$ & OR 0.59 (0.00-154.35) & 74 & \multirow[t]{3}{*}{ Very low } \\
\hline & & & Second twin (non-cephalic) & $1 / 5$ & $0 / 4$ & OR $1.00(0.02-40.28)$ & $N / A$ & \\
\hline & & & Both twins & $2 / 11$ & $2 / 10$ & OR $0.76(0.03-17.34)$ & 48 & \\
\hline \multirow{3}{*}{$\begin{array}{l}\text { Respiratory distress } \\
\text { syndrome (RDS) }\end{array}$} & \multirow[t]{3}{*}{$25^{+0}-27^{+6}$} & \multirow[t]{3}{*}{2} & First twin (cephalic) & $13 / 14$ & $15 / 15$ & OR $0.23(0.01-6.25)$ & N/A & \multirow[t]{3}{*}{ Very low } \\
\hline & & & Second twin (non-cephalic) & $13 / 14$ & $13 / 15$ & OR 1.60 (0.12-20.99) & $N / A$ & \\
\hline & & & Both twins & $26 / 28$ & $28 / 30$ & OR 0.77 (0.10-5.87) & 0 & \\
\hline
\end{tabular}

GA gestational age, CS caesarean section, VD vaginal delivery, $n$ number of cases within exposure group, $N$ total number in exposure group, OR odds ratio, $C I$ confidence interval, Severe Brain Injury defined as intraventricular hemorrhage grade $\geq 3$ or periventricular leukomalacia, N/A not applicable. *Based on the Grading of Recommendations Assessment, Development and Evaluation quality of evidence assessment (GRADE) approach 


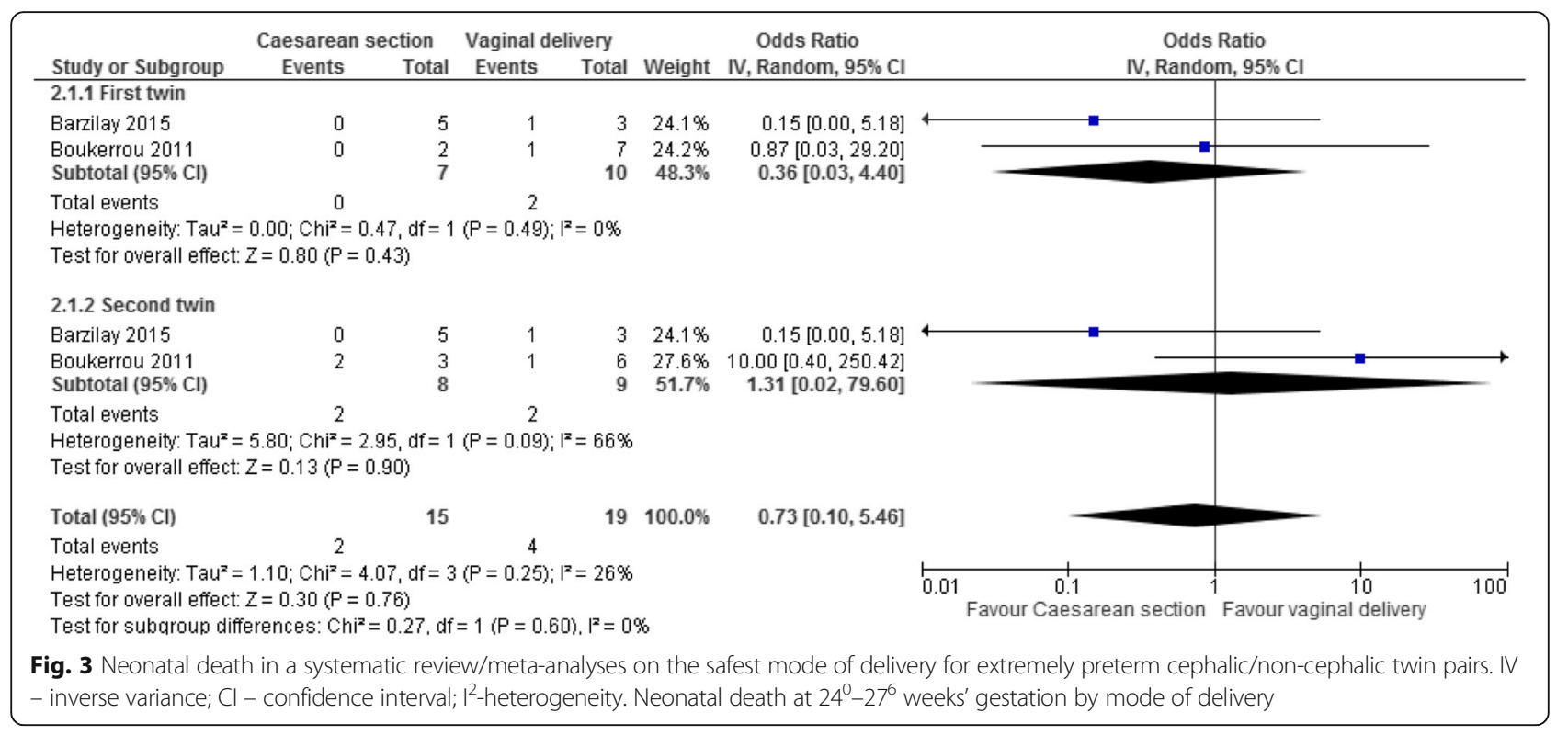

injury alone for the cephalic first twins, noncephalic second twins and when both twins were considered together.

\section{Strengths and limitations}

This systematic review has some strengths, including its focus on a specific clinical dilemma for which consensus is lacking thus far. We strove to provide a clinically relevant assessment of the evidence regarding the safest mode of delivery for extremely preterm twins, and therefore we accounted for gestational age, birth order and presentation of each twin in our study design, as each of those could impact neonatal outcomes. We aimed at controlling the four major confounders of outcome in extremely preterm births (caesarean section for fetal distress, outborn status, ANCS use and clinical chorioamnionitis). Furthermore, the safest mode of delivery for twins cannot be inferred from singleton data as twinning itself may affect outcomes [45] and outcomes in both twins have to be looked at since the impact on both should be considered when choosing a mode of delivery.

Our systematic review also has limitations, the main one being the lack of primary randomized data on the safest mode of delivery of extremely preterm infants. Although the most ideal study design would be a randomized controlled trial, previous RCTs in singletons have failed [46-48], and hence it is unlikely that another large-enough RCT will be mounted in the near future.

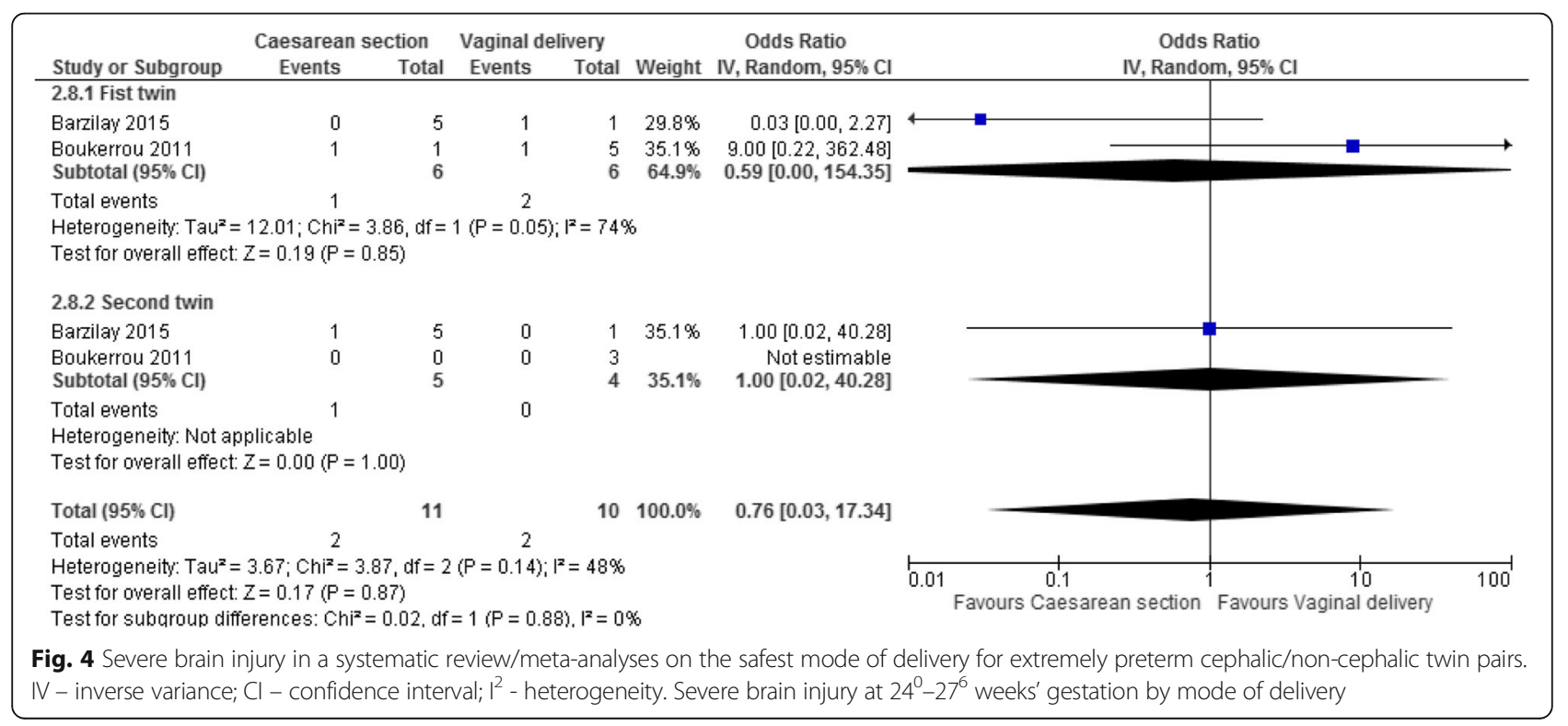




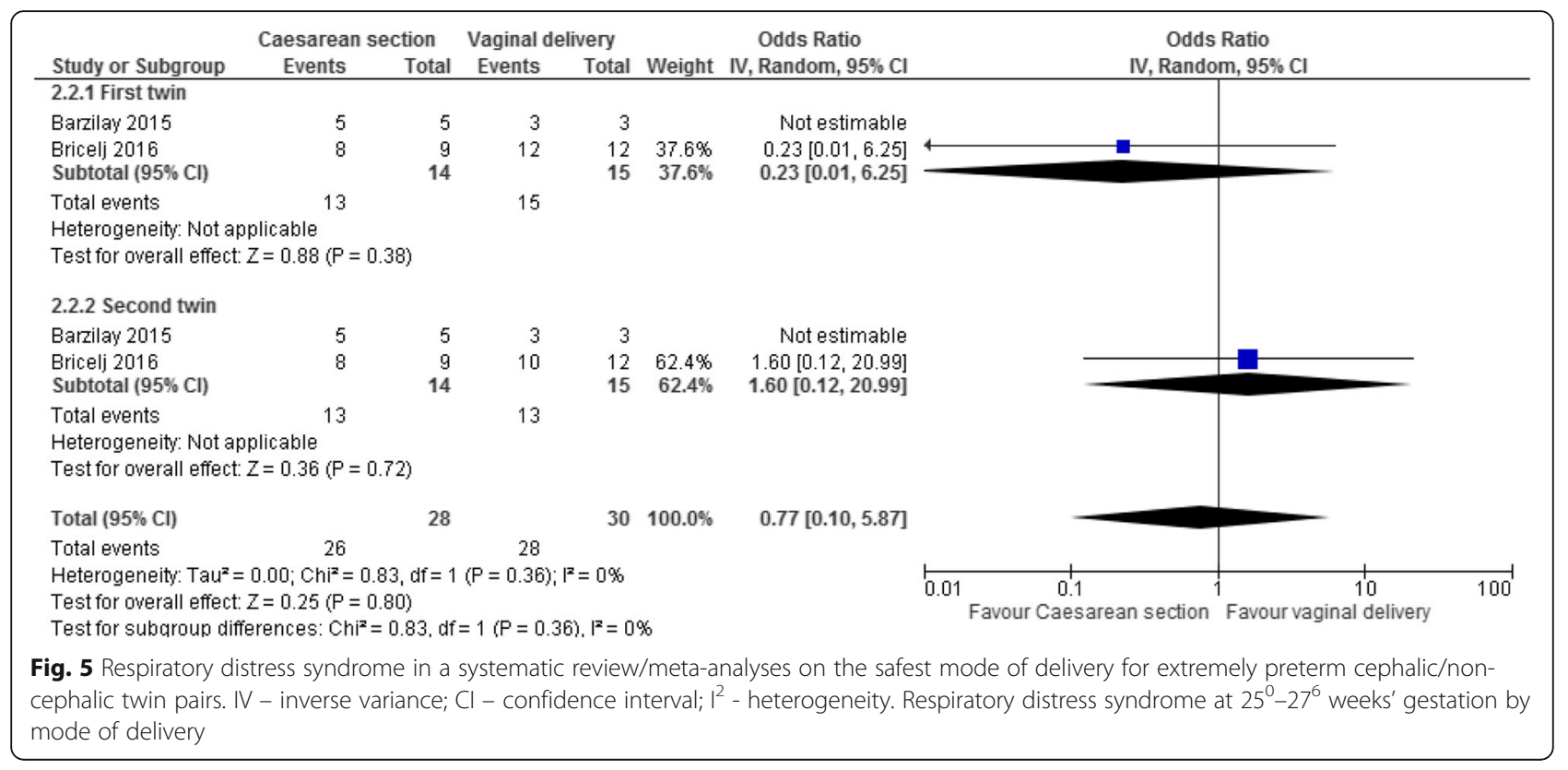

We therefore must rely on alternative research methodology. The observational data were scarce in terms of the number of extremely preterm twins available for analyses, which may be the reason for lack of significant differences, even in our pooled data, between outcomes after caesarean and vaginal delivery. Moreover, although we addressed the most important confounder, active resuscitation, by requiring it for inclusion in the analysis, other key confounders were not available for our subpopulation in the primary studies, which may also contribute to the lack of significant differences. Additionally, over the 1994-2017 period, the quality and accuracy of ultrasound estimation of gestational age varied. It would have been preferable to have data according to planned mode of delivery, rather than actual, but this was not available.

Lastly, maybe the most striking limitation was the overall sparsity of available data from primary studies that met our inclusion criteria.

\section{Comparing our findings to existing literature}

In comparing our results to previous reviews on the impact of mode of delivery in twins, we found that some previous systematic reviews did not focus on the extreme preterm period, but rather on twins above 32 weeks of gestation or above $1500 \mathrm{~g}[49,50]$, while others were unable to control for gestational age in their analysis [51]. To our knowledge, only narrative reviews have addressed the mode of delivery of extremely preterm twins. The first one included data from the 1980's and early 1990's, which are not as relevant to current clinical decision making given the subsequent advances in neonatal management and survival [52]. Nevertheless, these authors concluded that: "Management of low birth weight nonvertex second twins remains controversial... The retrospective nature and possibility for type II error of the majority of studies examining safety of vaginal delivery of the $L B W$ nonvertex second twin makes definitive conclusions regarding vaginal delivery of these infants difficult." A more recent review encompassed three additional studies from the 2000's, but none of those stratified outcomes for twins below $1500 \mathrm{~g}$ or 34 weeks [53]. The authors concluded again that: "The optimal mode of delivery in the preterm twin gestation (particularly those less than $2000 \mathrm{~g}$ ) continues to be debated, data... remains limited."

Some individual cohort studies addressing the safest mode of delivery for first or second twins, with a birth weight below $1500 \mathrm{~g}$ or a gestational age less than 34 weeks have found a decrease in risk of death and/or morbidity with caesarean section [54-59] while others have not [28-30, 44, 60-65]. However, these studies neither stratified by gestational age less than 28 weeks nor by extremely low birth weight $(<1000 \mathrm{~g})$, nor by presentation of the second twin.

In extremely preterm twins, prior to 1994 and hence advent of antenatal corticosteroid therapy and other advances in neonatal management, some studies had found a decrease in the risk of mortality with caesarean section in second twins weighing 601-999 g [66] and those weighing less than $1000 \mathrm{~g}$ [67]. More recently, Thomas 2016 [68] found an increase in survival with caesarean section for multiples from 24 to 26 weeks' gestation presenting as non-footling breech, but that difference was no longer significant after adjustment for gestational age, chorioamnionitis and maternal age. 
This study did not stratify data by birth order, and included higher order multiples.

Garite 2004 [69] also found no significant difference in mortality according to mode of delivery in 24-26 week twins stratified by birth order but not by presentation. They hypothesized: "It may also be that adverse outcomes, which tend to dominate most studies, in second twins that are seen in vaginal deliveries may be related primarily to term or near-term babies." This would go along with our analyses, even though not significant, in which the point estimate favoured caesarean section for the cephalic first twins as well as when all twins were considered together but not for the second twin.

Yang 2005 [54] focused on non-cephalic second twins, and stratified for those weighing less than 500-1499 g, concluding that vaginal delivery increased the risk of mortality compared to caesarean section, even when comparing to caesarean section performed for the second twin in the context of a combined delivery. Wen 2004 [56], studying second twins in any presentation, found the same protective effect of caesarean section below 36 weeks, but not after 36 weeks, when the only increase in mortality for the second twin was in fact in the case of combined delivery. These observations suggest that in very preterm twins and likely extremely preterm twins, in contrast to higher gestational ages, the mode of delivery may interact in a different manner with birth order and presentation to influence mortality and morbidity. The exact gestational age at which such an interaction tips is unknown and warrants more research.

\section{Conclusion}

In this systematic review of the safest mode of delivery for extremely preterm cephalic/non-cephalic twin pairs, we did not find a significant reduction in the odds of our composite outcome, neonatal death and severe brain injury, with either mode of delivery. The extremely limited primary and clinically relevant data available highlights the need for further appropriately designed research regarding safest mode of delivery for extremely preterm twins. An appropriate method would have to include details relevant to clinical decision making in that field.

Future research should seek to understand the long term neurodevelopmental outcomes and maternal outcomes in relation to mode of delivery of extremely preterm twins.

\section{Additional files}

Additional file 1: Search strategy for a systematic review and metaanalysis on the safest mode of delivery for extremely preterm cephalic/ non-cephalic twin pairs. (DOC $124 \mathrm{~kb}$ )

Additional file 2: Secondary infant and maternal outcomes included in a systematic review and meta-analyses on the safest mode of delivery for extremely preterm cephalic/non-cephalic twin pairs. (DOC $31 \mathrm{~kb}$ )
Additional file 3: Summary table of excluded studies in a systematic review and meta-analyses on the safest mode of delivery for extremely preterm cephalic/non-cephalic twin pairs - author contacted but could not provide the necessary data or did not respond. (DOC $179 \mathrm{~kb}$ )

Additional file 4: GRADE assessment for the primary composite outcome (neonatal death and severe brain injury), neonatal death and respiratory distress syndrome in a systematic review and meta-analyses for the safest mode of delivery for extremely preterm cephalic/non-cephalic twin pairs. (DOC 61 kb)

\section{Acknowledgements}

We are grateful to the authors of the primary studies who have provided additional data for the meta-analyses: Malik Boukerrou and Pierre-Yves Robillard (CHR de la Réunion, groupe hospitalier Sud-Réunion, Centre d'Études Périnatales de I'Océan Indien (CEPOI); Eran Barzilay (Sackler School of Medicine, Tel Aviv University); Katja Bricelj (University Medical Centre, Ljubljana,Slovenia) and Isaac Blickstein (Kaplan Medical Center and Hadassah- Hebrew University school of Medicine, Jerusalem, Israel); Norman Ginsberg (Northwestern University Medical School, Chicago) and Priyanka Gupta (University College of Medical Sciences, Delhi). We value the contribution of Ms. Neera Bhatnager, BSC, MLIS, Head of Systems, Coordinator of Research and Graduate Education Support, Health Sciences Library, McMaster University, for her assistance in developing the search strategies. We thank Simran Sharma and Kristen Viaje for supporting administrative aspects of the study.

\section{Funding}

The authors declare no source of financial support of the study, including provision of supplies or services from a commercial organization. SDM is supported by a CIHR Canada Research Chair (950-229,920). CIHR had no role in the design and conduct of the study; collection, management, analysis, and interpretation of the data; preparation, review, or approval of the manuscript; and decision to submit the manuscript for publication.

\section{Availability of data and materials}

All data generated or analyzed during this study are included in this published article [and its supplementary information files].

\section{Authors' contributions}

CD contributed to the study conception, performed the searches, reviewed titles and abstracts, reviewed full text articles, extracted data, performed data analyses and drafted the manuscript. AMLM contributed to the study conception, performed the duplicate review of titles and abstracts, review of full text articles, and data extraction, as well as reviewed the manuscript. MG contributed to the study conception and reviewed the manuscript for important intellectual content. AM contributed to the study conception, providing clinical expertise to neonatal aspects of the study and reviewed the manuscript for important intellectual content. SDM conceived the study idea, supervised the project and reviewed the manuscript for important intellectual content. All authors read and approved the final manuscript.

\section{Ethics approval and consent to participate}

Not applicable.

\section{Consent for publication}

Not applicable.

\section{Competing interests}

The authors declare that they have no competing interests.

\section{Publisher's Note}

Springer Nature remains neutral with regard to jurisdictional claims in published maps and institutional affiliations.

\section{Author details}

'Department of Obstetrics \& Gynecology, McMaster University, 1280 Main St W, HSC 3N52B, Hamilton, ON L8S 4K1, Canada. ${ }^{2}$ Department of Health Research Methods, Evidence, and Impact, McMaster University, 1280 Main St W, Hamilton, ON L8S 4K1, Canada. ${ }^{3}$ Department of Pediatrics, McMaster University, 1280 Main St W, Hamilton, ON L8S 4K1, Canada. 
Received: 29 June 2017 Accepted: 31 October 2017 Published online: 29 November 2017

\section{References}

1. March of Dimes, PMNCH, Save the Children, World Health Organization. Born too soon: the global action report on preterm birth. World Health Organization. 2012.

2. Institute of Medicine. Preterm birth: causes, consequences, and prevention In: Behrman RE, Butler AS, editors. Neurodevelopmental, health, and family outcomes for infants born preterm. Washington, D.C: National Academy Press; 2007.

3. Räisänen S, Gissler M, Saari J, Kramer M, Heinonen S. Contribution of risk factors to extremely, very and moderately preterm births-register-based analysis of 1,390,742 singleton births. PLoS One. 2013;8:e60660.

4. Shaw GM, Wise PH, Mayo J, Carmichael SL, Ley C, Lyell DJ, et al. Maternal prepregnancy body mass index and risk of spontaneous preterm birth. Paediatr Perinat Epidemiol. 2014;28:302-11.

5. Ananth CV, Chauhan SP. Epidemiology of Periviable births: the impact and neonatal outcomes of twin pregnancy. Clin Perinatol. 2017;44(2):333-45.

6. Chasen ST, Spiro SJ, Kalish RB, Chervenak FA. Changes in fetal presentation in twin pregnancies. J Matern Fetal Neonatal Med. 2005;17:45-8.

7. Bergenhenegouwen L, Meertens L, Schaaf J, Nijhuis J, Mol B, Kok M, et al. Vaginal delivery versus caesarean section in preterm breech delivery: a systematic review. J Obstet \& Gynecol Reprod Biol. 2014;172:1-6.

8. Tucker-Edmonds B, McKenzie F, Macheras M, Srinivas SK, Lorch SA. Morbidity and mortality associated with mode of delivery for breech periviable deliveries. Am J Obstet Gynecol. 2015;213:70.e1-12.

9. Kayem G, Combaud V, Lorthe E, Haddad B, Descamps P, Marpeau L, et al. Mortality and morbidity in early preterm breech singletons: impact of a policy of planned vaginal delivery. J Obstet Gynecol Reprod Biol. 2015;192:61-5.

10. Grabovac M, Karim JN, Isayama T, Korale Liyanage S, McDonald SD. What is the safest mode of birth for extremely preterm breech singleton infants who are actively resuscitated? A systematic review and metaanalyses. BJOG. 2017. doi:10.1111/1471-0528.14938. [Epub ahead of print].

11. Barrett JFR, Hannah ME, Hutton EK, Willan AR, Allen AC, Armson BA, et al. A randomized trial of planned cesarean or vaginal delivery for twin pregnancy. N Engl J Med. 2013;369:1295-305.

12. Kilby MD, Bricker $L$ on behalf of the Royal College of Obstetricians and Gynaecologists. Management of monochorionic twin pregnancy. BJOG. 2016;124:e1-e45

13. Barrett J, Bocking A. The SOGC consensus statement: management of twin pregnancies. J SOGC. 2000;91:5-15.

14. Vayssiere C, Benoist G, Blondel B, Deruelle P, Favre R, Gallot D, et al. Twin pregnancies: guidelines for clinical practice from the French College of Gynaecologists and Obstetricians (CNGOF). J Obstet Gynecol Reprod Biol. 2011;156:12-7

15. Hayes EJ. Practice bulletin no. 169: multifetal gestations: twin, triplet, and higher-order multifetal pregnancies. Obstet Gynecol. 2016;128:e131-46.

16. Higgins JPT, Altman DG, Gotzsche PC, Juni P, Moher D, Oxman AD, et al. The Cochrane Collaboration's tool for assessing risk of bias in randomised trials. BMJ. 2011;343:d5928

17. Moher D, Liberati A, Tetzlaff J, Altman DG, Group P. Preferred reporting items for systematic reviews and meta-analyses: the PRISMA statement. Int J Surg. 2010;8:336-41.

18. Villar J, Cheikh Ismail L, Victora CG, Ohuma EO, Bertino E, Altman DG, et al. International standards for newborn weight, length, and head circumference by gestational age and sex: the newborn cross-sectional study of the INTERGROWTH-21st project. Lancet. 2014;384:857-68.

19. Lorenz JM. The outcome of extreme prematurity. Semin Perinatol. 2001;25:348-59.

20. Cunningham F, Leveno KJ, Bloom SL, Spong CY, Dashe JS, Hoffman BL, et al. Overview of obstetrics. In: Williams obstetrics, twenty-fourth edition. New York, NY: McGraw-Hill; 2013.

21. de Waal CG, Weisglas-Kuperus N, van Goudoever JB, Walther FJ, NeoNed Study G, Group LNFS. Mortality, neonatal morbidity and two year follow-up of extremely preterm infants born in The Netherlands in 2007. PLoS One. 2012;7:e41302.

22. Guyatt G, Oxman AD, Akl EA, Kunz R, Vist G, Brozek J, et al. GRADE guidelines: 1. Introduction-GRADE evidence profiles and summary of findings tables. J Clin Epidemiol. 2011;64:383-94.

23. Cochrane Community. RevMan 5 Download. [http://community.cochrane.org/ tools/review-production-tools/revman-5/revman-5-download]. Accessed Jun 8.
24. Sterne JA, Sutton AJ, loannidis JP, Terrin N, Jones DR, Lau J, et al. Recommendations for examining and interpreting funnel plot asymmetry in meta-analyses of randomised controlled trials. BMJ. 2011;343:d4002.

25. Schmitz T, Prunet C, Azria E, Bohec C, Bongain A, Chabanier P, et al. Association between planned cesarean delivery and neonatal mortality and morbidity in twin pregnancies. Obstet Gynecol. 2017;129:986-95.

26. Smith GC, Pell JP, Dobbie R. Birth order, gestational age, and risk of delivery related perinatal death in twins: retrospective cohort study. BMJ. 2002;325:1004.

27. Marttila R, Kaprio J, Hallman M. Respiratory distress syndrome in twin infants compared with singletons. Am J Obstet Gynecol. 2004;191:271-6.

28. Shinwell ES, Blickstein I, Lusky A, Reichman B. Effect of birth order on neonatal morbidity and mortality among very low birthweight twins: a population based study. Arch Dis Child Fetal Neonatal Ed. 2004;89: F145-8.

29. Vidovics M, Jacobs VR, Fischer T, Maier B. Comparison of fetal outcome in premature vaginal or cesarean breech delivery at 24-37 gestational weeks. Arch Gynecol Obstet. 2014:290:271-81.

30. Sheay W, Ananth CV, Kinzler WL. Perinatal mortality in first- and secondborn twins in the United States. Obstet Gynecol. 2004;103:63-70.

31. Smith GCS, Fleming KM, White IR. Birth order of twins and risk of perinatal death related to delivery in England, Northern Ireland, and Wales, 19942003: retrospective cohort study. BMJ. 2007;334:576.

32. Malloy $\mathrm{MH}$. Impact of cesarean section on neonatal mortality rates among very preterm infants in the United States, 2000-2003. Pediatrics. 2008;122:285-92.

33. Jain NJ, Kruse LK, Demissie K, Khandelwal M. Impact of mode of delivery on neonatal complications: trends between 1997 and 2005. J Matern Fetal Neonatal Med. 2009:22:491-500.

34. Markestad T, Kaaresen Pl, Ronnestad A, Reigstad H, Lossius K, Medbo S, et al Early death, morbidity, and need of treatment among extremely premature infants. Pediatrics. 2005;115:1289-98.

35. Hogberg U, Hakansson S, Serenius F, Holmgren PA. Extremely preterm cesarean delivery: a clinical study. Acta Obstet Gynecol Scand. 2006;85: $1442-7$

36. Usta IM, Nassar AH, Awwad JT, Nakad TI, Khalil AM, Karam KS. Comparison of the perinatal morbidity and mortality of the presenting twin and its COtwin. J Perinatol. 2002;22:391-6.

37. Usta IM, Rechdan JB, Khalil AM, Nassar AH. Mode of delivery for vertexnonvertex twin gestations. Int J Gynecol Obstet. 2005;88:9-14.

38. Tadic E, Stefanic-Mitrovic D, Milic N, Kulisic D, Baraka K. Should we increase the number of cases of cesarean sections?. [Croatian]. Gynaecologia et Perinatologia. 2003;12:33-6.

39. Sbeiti N, Ziedeh F, Ramadan M, Lababidi H, Rajab M. Outcomes of premature and very-low-birth-weight infants from 1991 to 2002. J Med Liban. 2005:53:162-7.

40. Gupta P, Faridi MM, Goel N, Zaidi ZH. Reappraisal of twinning: epidemiology and outcome in the early neonatal period. Singap Med J. 2014;55:310-7.

41. Ginsberg NA, Levine EM. Delivery of the second twin. Int J Gynecol Obstet. 2005;91:217-20.

42. Bricelj K, Tul N, Lasic M, Bregar AT, Verdenik I, Lucovnik M, et al. Respiratory morbidity in twins by birth order, gestational age and mode of delivery. J Perinat Med. 2016:44:899-902.

43. Boukerrou M, Robillard PY, Gerardin P, Heisert M, Kauffmann E, Laffitte A, et al. Modes of deliveries of twins as a function of their presentation. A study of 371 pregnancies. Gynecol Obstet Fertil. 2011;39:76-80.

44. Barzilay E, Mazaki-Tovi S, Amikam U, de Castro H, Haas J, Mazkereth R, et al. Mode of delivery of twin gestation with very low birthweight: is vaginal delivery safe? Am J Obstet Gynecol. 2015;213(219):e211-8.

45. Shinwell ES. Neonatal morbidity of very low birth weight infants from multiple pregnancies. Obstet Gynecol Clin N Am. 2005;32:29-38. viii

46. Viegas OA, Ingemarsson I, Sim LP, Singh $K$, Cheng M, Ratnam SS, et al. Collaborative study on preterm breeches: vaginal delivery versus caesarean section. Asia Oceania J Obstet Gynaecol. 1985;11:349-55.

47. Zlatnik FJ. The lowa premature breech trial. Am J Perinatol. 1993;10:60-3.

48. Penn ZJ, Steer PJ, Grant A. A multicentre randomised controlled trial comparing elective and selective caesarean section for the delivery of the preterm breech infant. Br J Obstet Gynaecol. 1996;103:684-9.

49. Hogle KL, Hutton EK, McBrien KA, Barrett JF, Hannah ME. Cesarean delivery for twins: a systematic review and meta-analysis. Am J Obstet Gynecol. 2003;188:220-7 
50. Steins Bisschop CN, Vogelvang TE, May AM, Schuitemaker NWE. Mode of delivery in non-cephalic presenting twins: a systematic review. Arch Gynecol Obstet. 2012;286:237-47.

51. Rossi AC, Mullin PM, Chmait RH. Neonatal outcomes of twins according to birth order, presentation and mode of delivery: a systematic review and meta-analysis. BJOG. 2011;118:523-32.

52. Boggess KA, Chisholm CA. Delivery of the nonvertex second twin: a review of the literature. Obstet Gynecol Surv. 1997;52:728-35.

53. Hui D, Barrett JFR. Mode of delivery in term and preterm twins: a review. Fetal Matern Med Rev. 2014;25:1-11.

54. Yang Q, Wen SW, Chen Y, Krewski D, Fung Kee Fung K, Walker M. Neonatal death and morbidity in vertex-nonvertex second twins according to mode of delivery and birth weight. Am J Obstet Gynecol. 2005;192:840-7.

55. Wen SW, Fung Kee Fung K, Oppenheimer L, Demissie K, Yang Q, Walker M. Neonatal morbidity in second twin according to gestational age at birth and mode of delivery. Am J Obstet Gynecol. 2004;191:773-7.

56. Wen SW, Fung Kee Fung K, Oppenheimer L, Demissie K, Yang Q, Walker M. Neonatal mortality in second twin according to cause of death, gestational age, and mode of delivery. Am J Obstet Gynecol. 2004;191:778-83.

57. Ziadeh SM, Badria LF. Effect of mode of delivery on neonatal outcome of twins with birthweight under $1500 \mathrm{~g}$. Arch Gynecol Obstet. 2000;264:128-30.

58. Herbst A, Kallen K. Influence of mode of delivery on neonatal mortality in the second twin, at and before term. BJOG. 2008;115:1512-7.

59. Chervenak FA, Johnson RE, Youcha S, Hobbins JC, Berkowitz RL. Intrapartum management of twin gestation. Obstet Gynecol. 1985:65:119-24.

60. Doyle LW, Hughes CD, Guaran RL, Quinn MA, Kitchen WH. Mode of delivery of preterm twins. Aust N Z J Obstet Gynaecol 1988;28:25-28.

61. Rydhstrom H. Prognosis for twins with birth weight less than 1500 $\mathrm{gm}$ : the impact of cesarean section in relation to fetal presentation. Am J Obstet Gynecol. 1990;163:528-33.

62. Davison L, Easterling TR, Jackson JC, Benedetti TJ. Breech extraction of lowbirth-weight second twins: can cesarean section be justified? Am J Obstet Gynecol. 1992;166:497-502.

63. Winn HN, Cimino J, Powers J, Roberts M, Holcomb W, Artal R, et al. Intrapartum management of nonvertex second-born twins: a critical analysis. Am J Obstet Gynecol. 2001;185:1204-8.

64. Caukwell S, Murphy DJ. The effect of mode of delivery and gestational age on neonatal outcome of the non-cephalic- presenting second twin. Am J Obstet Gynecol. 2002;187:1356-61.

65. Sentilhes L, Oppenheimer A, Bouhours AC, Normand E, Haddad B, Descamps $P$, et al. Neonatal outcome of very preterm twins: policy of planned vaginal or cesarean delivery. Am J Obstet Gynecol. 2015; 213(73):e71-73.e77.

66. Barrett JM, Staggs SM, Van Hooydonk JE, Growdon JH, Killam AP, Boehm $\mathrm{FH}$. The effect of type of delivery upon neonatal outcome in premature twins. Am J Obstet Gynecol. 1982;143:360-7.

67. Zhang J, Bowes WA Jr, Grey TW, McMahon MJ. Twin delivery and neonatal and infant mortality: a population-based study. Obstet Gynecol. 1996;88:593-8.

68. Thomas PE, Petersen SG, Gibbons K. The influence of mode of birth on neonatal survival and maternal outcomes at extreme prematurity: a retrospective cohort study. Aust N Z J Obstet Gynaecol. 2016;56:60-8.

69. Garite TJ, Clark RH, Elliott JP, Thorp JA. Twins and triplets: the effect of plurality and growth on neonatal outcome compared with singleton infants. Am J Obstet Gynecol. 2004;191:700-7.

\section{Submit your next manuscript to BioMed Central and we will help you at every step:}

- We accept pre-submission inquiries

- Our selector tool helps you to find the most relevant journal

- We provide round the clock customer support

- Convenient online submission

- Thorough peer review

- Inclusion in PubMed and all major indexing services

- Maximum visibility for your research

Submit your manuscript at www.biomedcentral.com/submit
Biomed Central 